\title{
CrimRxiv
}

\section{The Gozi group: A criminal firm in cyberspace?}

Jonathan Lusthaus, Jaap Van Oss, Philipp Amann

Published on: Feb 17, 2022

DOI: $10.21428 / c b 6 a b 371 . e 1600 b e 7$

License: Creative Commons Attribution 4.0 International License (CC-BY 4.0). 
